\title{
MANDIBULAR CONDYLE FRACTURES; A 2 YEARS STUDY AT LIAQUAT UNIVERSITY HOSPITAL
}

1. Associate Professor Oral \& Maxillofacial Surgery LUMHS

2. Research Officer Oral \& Maxillofacial Surgery LUMHS

3. Senior Dental Surgeon LUH Hyderabad

4. Assistant Professor Oral \& Maxillofacial Surgery LUMHS

5. MSc Trainee Oral \&

Maxillofacial Surgery LUMHS

Correspondence Address:

Dr. Salman Shams

B $1 / 2$ Sajjadabad Society

Near Citizen Colony,

Hyderabad-Sindh

salman_2510@hotmail.com

Article received on: 22/03/2016

Accepted for publication: 10/05/2016

Received after proof reading: 26/05/2016
Dr. Syed Ghazanfar Hassan ${ }^{1}$, Dr. Salman Shams², Dr. Mujeeb Rehman ${ }^{3}$, Dr. Suneel Kumar ${ }^{4}$, Dr. Shuja Hamid 5

ABSTRACT... Objectives: To analyze frequency, gender, age, cause of injury and type/location of Condylar fracture among patients reported at Liaquat university hospital Hyderabad. Setting of Study: This study was conducted at Oral \& Maxillofacial Surgery Department, Faculty of Dentistry, Liaquat University Hospital, and Hyderabad. Period: $1^{\text {st }}$ February 2013 to $31^{\text {st }}$ January 2015. Methodology: The statistics of 108 patients both males and females who had been affected with mandibular Condyle fracture were prospectively reviewed. Patient's data including gender, age, cause of injury, type of Condylar fracture were recorded on Proformas and then prospectively analyzed. Results: Out of 108 patients $81(75 \%)$ male and $27(25 \%)$ female were affected with mandibular Condylar fracture. The common age group was $2^{\text {nd }}$ decade of life (11-20 years). Most common cause of injury was fall in 51 cases (47.2\%) followed by RTA in 43 cases $(39.8 \%)$. Sub condylar fracture was most common type of fracture occurred i.e in 56 cases (51.8\%). Conclusion: Children's are commonly affected with mandibular Condyle fracture \& fall was the most common etiology in our study sample that explains the association between fall and Condylar trauma. The second common etiological factor was Road traffic accident for Sub condylar fractures in our study sample.

Key words: $\quad$ Fracture, Condylar, Fall, RTA, Children's

Article Citation: Hassan SG, Shams S, Rehman M, Kumar S, Hamid S. Mandibular co ndyle fractures; a 2 years study at liaquat university hospital. Professional Med J 2016;23(6):705-708. DOI: 10.17957/TPMJ/16.2905

\section{INTRODUCTION}

Among all the facial skeletal bones, mandible is the strongest having horse shoe shape and most solid bone but however, it is also the most commonly fractures, mainly because of its protruded position in face than any other facial skeletal bone. ${ }^{1}$ Because of prominent pose of the lower jaw, mandibular fractures are encountered as the most common facial skeletal fractures accounting for $36 \%$ to $59 \%$ of all maxillofacial fractures. ${ }^{1}$ The mandible includes mechanically fragile anatomical sites, such as the angle region of mandibular than condylar region of mandibular, and the symphysis. ${ }^{2}$ Parasymphysis area is more frequently involved in mandibular fractures than Condylar finally and sub condylar areas. ${ }^{3}$ According to Olson et $\mathrm{al}^{4}$ study results mandibular Condyle was most frequently fracture in fractures of mandible $19-52 \%$, followed by the angle region of mandible and the mandibular symphysis.
Most authors postulated that mandibular Condyle is the $2^{\text {nd }}$ most common fracture in mandible with the ratio of 2: 1 (Male-Female). Fracture of Condyle is a defensive mechanism which prevents fracture of the base of the skull. ${ }^{5}$ Fracture of mandibular Condyle can also take place in segregation as a result of direct impact or it is frequently associated with fracture of parasymphysis region. The fractures of mandibular Condyle have been classified in different ways like intracapsular / extra capsular, Head of Condyle either High or Low, Sub condylar, Condylar Neck and unilateral / bilateral based on the site. ${ }^{6}$ Road traffic accidents, accidental falls, interpersonal violence, sport injuries, and industrial / mechanical trauma are the mostly seen causes of mandibular Condylar fractures. $^{7,8}$

Complications that can be encountered with the fracture of mandibular Condyle are pain either mild or severe, limited \& restricted mandibular movement, muscle spasm with or 
without, deviation, disturbed occlusion, and sometimes pathological alterations in the TMJ (Temporomandibular joint), facial asymmetry, osteonecrosis, and finally ankylosis..$^{9,10,11}$ Various treatment options are used to treat mandibular Condyle fractures which include non-surgical and surgical treatment. In the treatment of mandibular Condyle fracture, conservative treatment for Condylar fractures closed reduction followed by functional therapy and in surgical treatment option open reduction and internal fixation will be done. $^{12}$

\section{METHODOLOGY}

All the patients reporting with mandibular Condylar fracture irrespective of age and gender for management were requested and enrolled in the study. A thorough detailed history and clinical (Intraoral/ Extraoral) examination was performed on all the patients reporting at department of Oral \& Maxillofacial surgery, Faculty of Dentistry, Liaquat University Hospital, Hyderabad. Those patients who were suspected of having mandibular Condylar fractures were prescribed Orthopantomogram (OPG), Postero-anterior view and Lateral oblique view of mandible. Final diagnosis of mandibular Condylar fractures was made with the help of clinical and radiographic findings. Patient's data including gender, age, and cause of injury, location of Condylar fracture (head, neck and sub condyle) were recorded on Proformas and then prospectively analyzed. All the recorded data was entered and finally analyzed with the help of SPSS software, (version 20.0)

\section{RESULTS}

Out of 108 study sample most patients were males 81 (75\%), with females accounting for 27 cases (25\%) (Figure 1). The Condylar fractures was higher in frequency between the age group of 1120 , where we reported 41 cases (37.9)followed by 21-30 years age group with 31 cases(28.7) (Table-I). The overall etiology of mandible Condylar fractures was found to be multifactorial, but fall 51 cases (47.2\%) and followed by RTA 43 cases $(39.8 \%)$ were found to be the most principal etiological factors in our study sample
(Table-II). According to location the sub condylar fractures were in highest frequency i.e. 56 cases (51.8\%) followed by Condylar neck fractures 38 cases $(35.1 \%)$ see table (Table-III).

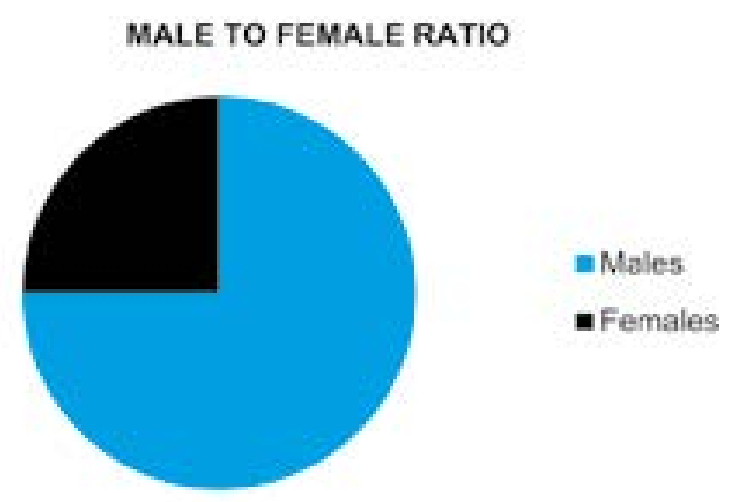

Figure-1. Showing Male to Female Ratio

\begin{tabular}{|c|c|c|}
\hline Age Group & $\begin{array}{c}\text { Total Patients with } \\
\text { Condylar Fractures }\end{array}$ & $\%$ \\
\hline $1-10$ Years & 18 & $16.66 \%$ \\
\hline $11-20$ Years & 41 & $37.96 \%$ \\
\hline $21-30$ Years & 31 & $28.70 \%$ \\
\hline $31-40$ Years & 12 & $11.11 \%$ \\
\hline $41-50$ Years & 06 & $5.55 \%$ \\
\hline Table-I. Frequency of condylar fractures with age \\
\hline
\end{tabular}

\begin{tabular}{|l|c|c|}
\hline Cause of Injury & $\begin{array}{c}\text { Total Patients with } \\
\text { Condylar Fractures }\end{array}$ & $\%$ \\
\hline Fall & 51 & $47.2 \%$ \\
\hline RTA & 43 & $39.8 \%$ \\
\hline Sports Injuries & 10 & $9.25 \%$ \\
\hline Assault & 04 & $3.70 \%$ \\
\hline
\end{tabular}

Table-II. Showing different causes of injuries

\begin{tabular}{|l|c|c|}
\hline Fracture location & $\begin{array}{c}\text { Total Patients with } \\
\text { Condylar Fractures }\end{array}$ & $\%$ \\
\hline Sub condyle fracture & 56 & $51.8 \%$ \\
\hline Condylar neck & 38 & $35.1 \%$ \\
\hline Condylar head & 14 & $12.9 \%$ \\
\hline \multicolumn{2}{|c|}{ Table-III. Distribution according to fracture location }
\end{tabular}

\section{DISCUSSION}

Previous studies indicated that the occurrence of Condylar fracture of mandible was the $2^{\text {nd }}$ most 
common fractures in mandible with ratio of $2: 1$ (Male: Female).

In this present study males constitute $(75 \%)$ of the total cases which supports the statistics of study carried out by Larsen and Nielsen ${ }^{13}$ in which the male female ratio was $3: 1$ \& also its supports the findings of Badar $\mathrm{MA}^{14}$ in 2014 . Whereas, the Condylar fractures in females remains low as compare to males due to females remain at home rather than males who actively participate in outside works.

In our study data the Condylar fractures was found highest $(37.9 \%)$ in Ist decade followed by $2^{\text {nd }}$ decade, which was completely opposing the findings of the study carried out by Morgan ${ }^{15}$ and Amaratunga ${ }^{16}$ which they found Ist decade was the most affected group.

In study conducted by Lida and Matsuya ${ }^{17}$ also observed Condylar fractures were being more frequent in children less than 14 years of age, particularly in those below 6 years.

But a study result of Newman ${ }^{18}$ et al was indicated that Condylar fractures were between 17 and 32 years of age, which almost closely match the figures of present study.

Fall is the most common cause of Condylar fracture in the our study with 51 cases $47.2 \%$, this data is supported by Murad $\mathrm{N}^{19}$ and Ahmad ${ }^{12}$ who also demonstrate fall as the most common etiological factor for these fractures. The results of the present study showed that road traffic accidents was the second common etiological factor for Condylar fracture which is dissimilar to the study carried out by Sawazaki ${ }^{20}$ et al who reported RTA as most common cause with 55.33\% of patients. Other causes comprise sports injuries $\&$ assaults.

A study conducted Abbas et $\mathrm{al}^{3}$ described RTA was the common etiological factor of mandibular Condylar fractures. However house hold violence remains unreported in this study due to the social boundaries.
Present study reported highest number of patients with sub condylar fractures with $39.8 \%$. The study conducted by Viveka and Reddy ${ }^{22}$ who reviewed 175 cases of Condylar fractures and showed sub condylar fractures was the common in total cases i.e. 88, than Condylar neck and Condylar head.

\section{CONCLUSION}

Results of our study clearly showed that children's were the more commonly affected with Mandibular Condylar fracture, and fall was the main etiological factor among the 108 study sample which indicates close mechanical association between Condylar injury and children's. The Road traffic accident was $2^{\text {nd }}$ most common etiology in our study sample. Sub condylar fractures were seen to be the most frequent.

The results obtained by our study sample can be useful in describing the pattern and etiology of mandibular Condylar fractures in our society and may be taken as the guidance for parents / local Government department make campaigns or educate the public to look after their children's during playing activities or other activities in which there is risk for fall .

Copyright (C) 10 May, 2016.

\section{REFERENCES}

1. Zachar MR, Labella C, Kittle CP, Baer PB, Hale RG, Chan RK. Characterization of mandibular fractures incurred from battle injuries in Iraq and Afghanistan from 2001-2010. J Oral Maxillofac Surg. 2013; 71:73442.

2. Gassner R, Tuli T, Hächl O, Rudisch A, Ulmer H. Craniomaxillofacial trauma: a 10 year review of 9,543 cases with 21,067 injuries. J Craniomaxillofac Surg 2003; $31: 51-61$

3. Abbas I, Ali K, Mirza YB. Spectrum of mandibular fractures at a tertiary care dental hospital in Lahore. J Ayub Med Coll Abbottabad. 2003; 15:12-14.

4. Olson RA, Fonseca RJ, Zeitler DL, Osbon DB. Fractures of the mandible: a review of 580 cases. J Oral Maxillofac Surg 1982; 40:23-8.

5. P. A. Banks, "Pragmatic Approach to the Management of Condylar Fractures," Int Jr of Oral and Maxillo Surg, 1998;27(4):244-246.

6. R. R. Bos, R. P. Ward Booth and L. G. de Bont, 
"Mandibular Condyle Fractures: A Consensus," British Jr of Oral and Maxillo Surg 1999; 37(2): 87-89.

7. Joshi SR, Saluja H, Pendyala GS, Chaudhari S, Mahindra $U$, Kini $Y$. Pattern and prevalence of maxillofacial fractures in rural children of central maharashtra, India. A retrospective study. J Maxillofac Oral Surg. 2013; 12:307-11.

8. Yamamoto K, Matsusue Y, Horita S, Murakami K, Sugiura T, Kirita T. Maxillofacial fractures sustained in bicycle accidents. J Oral Maxillofac Surg. 2011; 69:155-60.

9. Ellis III E, Throckmorton GS. Treatment of mandibular condylar process fractures: biological considerations. J Oral Maxillofac Surg 2005; 63: 11534.

10. Long X, Goss AN. A sheep model of intracapsular condylar fracture. J Oral Maxillofac Surg 2007; 65: 1102-8.

11. Qudah A, Qudeimat A, Maaita AL Condylar fractures in children. $\mathrm{J}$ Cranio-Maxillofac Surg 2005; 33:30-36.

12. Villarreal PM, Monje $F$, Junquera LM, Mateo J, MorilloAJ, Gonzalez C. Mandibular condyle fractures: determinants of treatment and outcome. J Oral Maxillofac Surg 2004; 62: 155-63.

13. Larsen OD NA. Mandibular fractures: An analysis of their etiology and location in $\mathbf{2 8 6}$ patients. Scand $J$ Plast Reconstr Surg. 1976;10:213-18.

14. Badar MA, Syed SA. Etiology of Mandibular Condylar
Fractures; A Study From Tertiary Care Hospital of Lahore. PODJ 2014; 34(1):42-45.

15. Morgan WC. Pediatric mandibulars farctures. Oral Surg 1975; 40:320-26.

16. Amaratunga S. Mandibular fracture in children. A study of clinical aspects, treatment need and complication. J Oral nad Maxillofca Surg 1988; 46(8):637-40.

17. lida S, Matsuya T. Paediatric maxillofacial fractures: their etiological characters and fracture patterns. $J$ Craniomaxillofac Surg. 2002; 30:237-41.

18. Newman L. A clinical evaluation of the long-term outcome of patients treated for bilateral fracture of the mandibular condyles. $\mathrm{Br} \mathrm{J}$ Oral Maxillofac Surg. 1998; 36:176-79.

19. Murad N, Qaimuddin, Khan M, Shah SMA. Condylar Fractures in Childrens -A Study. PODJ 2010; 30(2):291-294.

20. Sawazaki et al. Incidence and Patterns of Mandibular Condylar Fractures. J Oral Maxillofac Surg 2010.

21. M. Schneider UE. Classification of condylar process fractures. 1972. p. 10-15.

22. Viveka N, Reddy V, et al. Analysis of Patterns and Treatment Strategies for Mandibular Condyle Fractures: Review of 175 Condyle Fractures with Review of Literature. 2013; 12(3):315-20.

\section{AUTHORSHIP AND CONTRIBUTION DECLARATION}

\begin{tabular}{|c|c|c|c|}
\hline Sr. \# & Author-s Full Name & Contribution to the paper & Author $=$ s Signature \\
\hline 1 & Dr. Syed Ghazanfar Hassan & Concept Development & \\
\hline 2 & $\begin{array}{l}\text { Dr. Salman Shams } \\
\text { Dr. Muieeb Rehman }\end{array}$ & $\begin{array}{l}\text { Principal Investigator, } \\
\text { Drafting, Data Collection, } \\
\text { Compiling } \\
\text { Data Collection }\end{array}$ & \\
\hline & 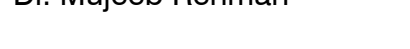 & 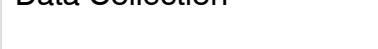 & \\
\hline 4 & Dr. Suneel Kumar & Data Analysis & \\
\hline 5 & Dr. Shuja Hamid & References & \\
\hline
\end{tabular}

